\title{
THE USE OF ILLUSTRATION IN BIOCHEMISTRY TEACHING AND LEARNING
}

\author{
AZILA ADNAN*
}

\begin{abstract}
Biochemistry is known as a complex course, especially the metabolic pathway topics. The main issue that instigate this initiative is the learners' difficulty in understanding metabolic pathway topic(s), resulting in uninteresting learning environment. Hence, 'the metabolic town' illustration, that depicts three metabolic pathways (glycolysis, Krebs cycle, and electron transport chain) is used as an initiative to revive learners' enthusiasm, which could breed interest and motivation to study this course. Trials were conducted with 35 students of Crop Science learners from the Faculty of Fisheries and Food Science, Universiti Malaysia Terengganu. Eighty-six percent (86.2\%) responded 'strongly agree' and 13.8\% responded 'agree' that the overall learning experience through the use of this illustration has created a positive and fun environment. Additionally, around 79\% learners responded 'strongly agree' that their knowledge on these topics have improved while $17.2 \%$ responded 'agree'. Nearly $100 \%$ of the learners agreed thus establish the connection between the lecture notes and the illustration. Other than that, from an intrinsic aspect, $72.4 \%$ of learners firmly agreed that this illustration aided their interest and motivation towards Biochemistry subject; while the other $27.6 \%$ agreed. $89.6 \%$ who answered strongly agreed showed that they are in favor of the use of illustration for revision while the rest agreed. Consequently, $86.2 \%$ of learners strongly agreed that the illustration boosted their understanding and boost their imagination, and the other $13.8 \%$ 'agreed'. This study investigates how an illustration of analogy could improve the learning process.
\end{abstract}

Keywords: Biochemistry; Learning; Illustration; Interest; Motivation

\section{INTRODUCTION}

Many topics in Biochemistry are tough for learners to learn, especially the mechanisms and metabolic pathways in metabolism topics. Since notes normally consist of verbose words in a form of papers/textbooks, learners usually learn and revise by reading texts. As visual explanations can visibly display mechanisms and processes of the metabolic pathway system, creating an illustration could benefit teaching and learning mechanism.

For learners, visual representations are important. For instance, illustration can assist in the process of understanding a topic. Few educators accept illustration as an applicable teaching tool in the classroom. It is undeniable that it is hard to 'imagine' biochemistry. Visual portrayals are significant because they help to make the unseen seen and the complex metabolic pathway becomes simplified (Quillin and Thomas, 2015). Visualization is a process of making an object, an event, or a situation visible to one's imagination by mentally constructing or recalling an image. Educators may use visualization with learners as an image creation exercise before creating a work of art. Visualization helps the learners to draw on their past knowledge and be innovative in expanding their thought. Educators can also use a variety of visual stimuli (e.g. illustrations, photographs, reproductions, videos, real objects, graphics) to assist learners in 
generating ideas for different kinds of work in all kind of sciences and arts. Embedding illustration in learning encourages visual learners and creative thinkers to take a new perspective on science learning and high-quality illustrations can become science resources (Sevarkadiyon and Parimalafathima, 2019).

The best illustration and lecture notes work closely to create meanings. Young learners are naturally attracted to illustrations than adult learners (Arts Council England). Previous research by Carney and Levin (2002) investigated at adjunct transformational (mnemonic) images as aids for learners to learn from the text (McCormick and Levin, 1987). In the last decade, Dretzke (1993) investigated the influences of mnemonic illustrations on youths (1729 years of age), middle-aged (40-50 years of age), and older (60-84 years of age) adults. Few recommendations by Carney and Levin (2002) can be considered for the teaching and learning process, which include:

1) Learning advantages arise when photos and text include fun or positive information. Decorative illustrations can help make the text/content more appealing, but they are unlikely to achieve the desired results in terms of understanding, remembering, or applying text content.

2) Easy-to-follow texts that are highly concrete and engaging (e.g. interesting narrative passages) quickly produce visual imagery in students but then again, they are unlikely to give additional cognitive benefits from the use of images.

3) To optimize the advantages of pictures, guide learners to do something with a picture that generates a controllable object, such as marking the features of the illustration (Peeck, 1993) or structuring the process so that learners are confident to create a true visual representation of the passage (e.g. Rubman and Waters, 2000).

4) The imagination idea of The Metabolic Town was generated from the "Where's Wally" cartoon/book series. The story and illustration depict dozens or more citizens doing a variety of amusing things at a given location. Hence, it is an analogy to a human body, which is made up of thousands of cells and associated molecules that carry out amazing and incredible functions at similar/different locations.

Hence, by implementing 'the metabolic town' illustration in teaching and learning, it could boost learner's emotions, understanding, interest and motivation towards these metabolic pathway topics. The illustration could also act as a supplementary tool that could help the educator/teacher to establish, explain, establish and correlate vivid conceptions, and better understandings to make learning more genuine, exceptional, motivating, inviting, and vibrant.

The main hypothesis in this study:

Illustration has the capacity to develop positive and significant relationship with enhanced learning process.

\section{MATERIALS AND METHODS}

35 students of the Crop Science program from the Faculty of Fisheries and Food Science, Universiti Malaysia Terengganu, Malaysia, Semester II 2019/2020 participated in this study. The semester commenced in early February and ended in May 2020. The study covered learning experience, knowledge improvement, relationship between illustrations and the original lecture notes, interest and motivation towards Biochemistry subject, aid in the revision process, and understanding of the three metabolic pathways (e.g. glycolysis, Krebs cycle, and electron transport chain). The metabolic town illustration was presented to the participants, followed by a survey for their feedbacks. The illustration was proposed to the teaching team 
and it was agreed upon to be used for further expansion, which involved further metabolic pathways that are related to the three metabolic pathways mentioned previously.

The metabolic town illustration is crafted and initiated in February 2020 using Microsoft Office and Canva tools, with some imaginative concepts. The little town/neighborhood (Figure 1), depicts the connection of the three metabolic pathways (e.g. glycolysis, Krebs cycle, and electron transport chain). Glycolysis is the initial pathway that occurs in cytosol, which at the end will produce pyruvate and NADH molecule (will go to Electron Transport Chain pathway later). The pyruvate produced will be oxidized to Acetyl CoA (aerobic condition) molecule before entering Krebs Cycle. The Krebs cycle will produce GTP, FADH 2 , and NADH. The FADH 2 and NADH (electron carrier) will be shuttled through and will get involved in the Electron Transport Chain (ETC) pathway (in the inner membrane of mitochondria). The ETC process is ultimately the biggest ATP provider in the metabolic system. In this cascade, the electrons that are carried by NADH and $\mathrm{FADH}_{2}$ will move from Complex I to Coenzyme Q, then to Complex III and subsequently to Cytochrome C. Finally, the electron will be accepted by the oxygen molecule (final electron acceptor), which at the end will produce water molecule. The ETC is following a theory called 'chemiosmosis' that involve electron movement, pumping out of hydrogen ion, and ATP production by ATP synthase enzyme. This relationship is being crafted in the form of a little town/neighborhood in one story line.

Some feedbacks on the survey of the drawing theme were stated below:

Question: What is your favorite part of this illustration?

Answers: "story theme, idea and color; idea, storylines and the objects resembling the molecule; it's colorful and I like it.

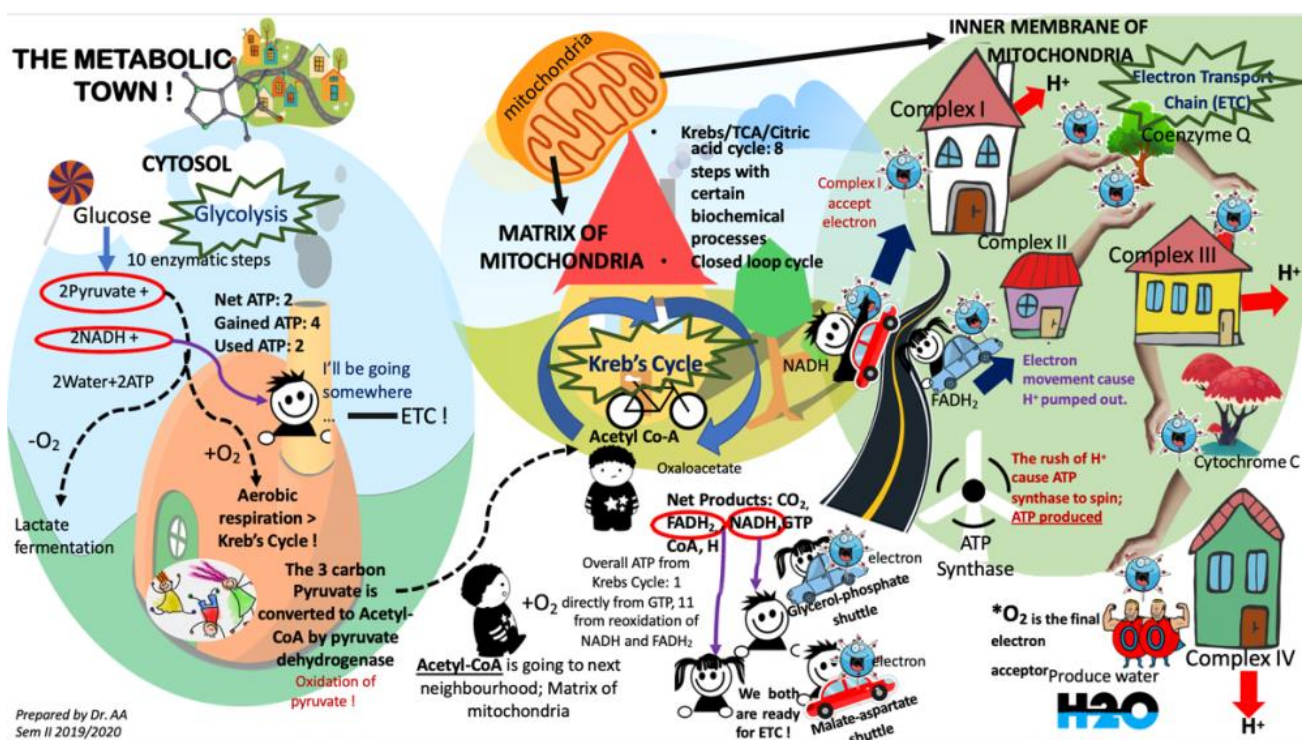

Figure 1: The metabolic town illustration

\section{RESULTS AND DISCUSSION}

Figure 2 illustrates the responses from the learners after using the metabolic town illustration as one of the learning tools for glycolysis, Krebs cycle, and electron transport chain topic. 86\% of 35 learners strongly agreed that the illustration provided a fun and positive learning experience, while the remaining $14 \%$ agreed. 


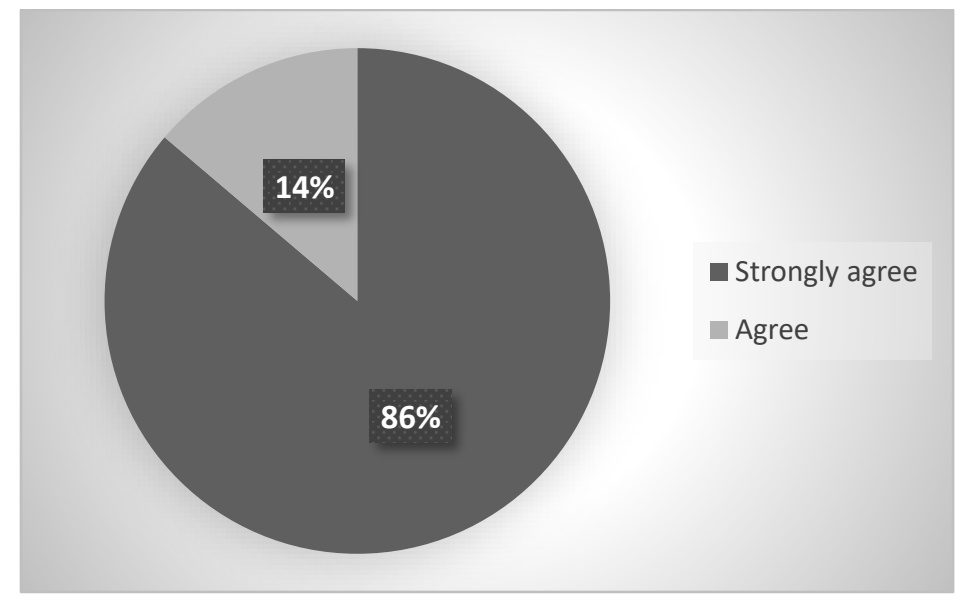

Figure 2: Learning experience when using metabolic town illustration

Meanwhile, based on Figure 3, 79\% of the learners strongly agreed that the illustration improved their knowledge of the three metabolic pathway topics while $17 \%$ agreed on this. However, one respondent or $4 \%$ had a contradicting opinion.

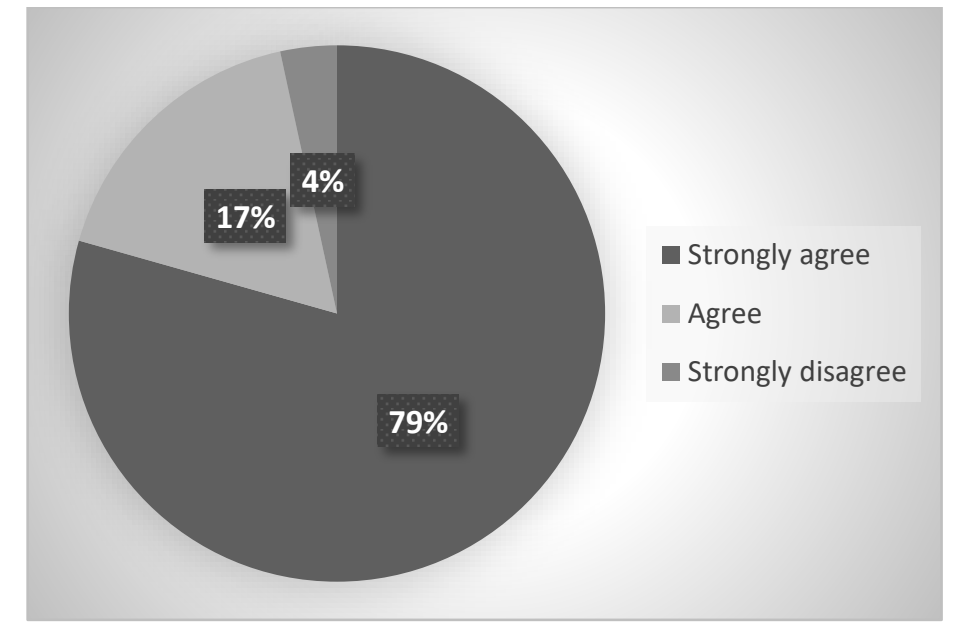

Figure 3: Knowledge improvement on the particular topics when using metabolic town illustration

As one of the aims and strategies is to improve students' understanding of the relationship of glycolysis, Krebs cycle, and electron transport chain pathway, it can be seen in Figure 4 that $79 \%$ of the learners can establish the relationship among these three metabolic pathways with the actual lecture notes. 


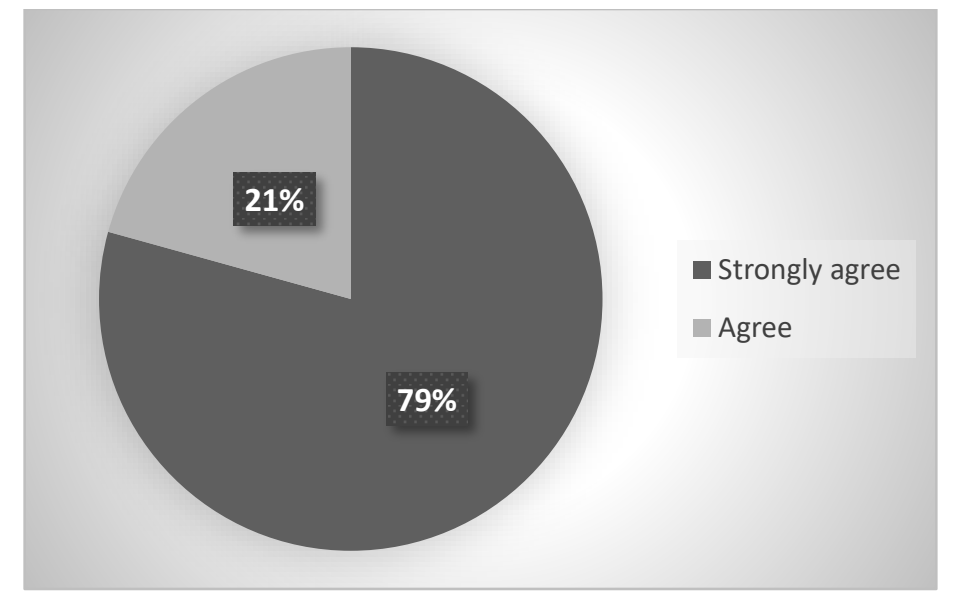

Figure 4: Establishing a relationship between the illustration with the lecture notes.

The pie chart below (Figure 5) shows that $72 \%$ of the students strongly agree that the illustration helped in enhancing their interest and motivation. The rest of $28 \%$ agreed with this.

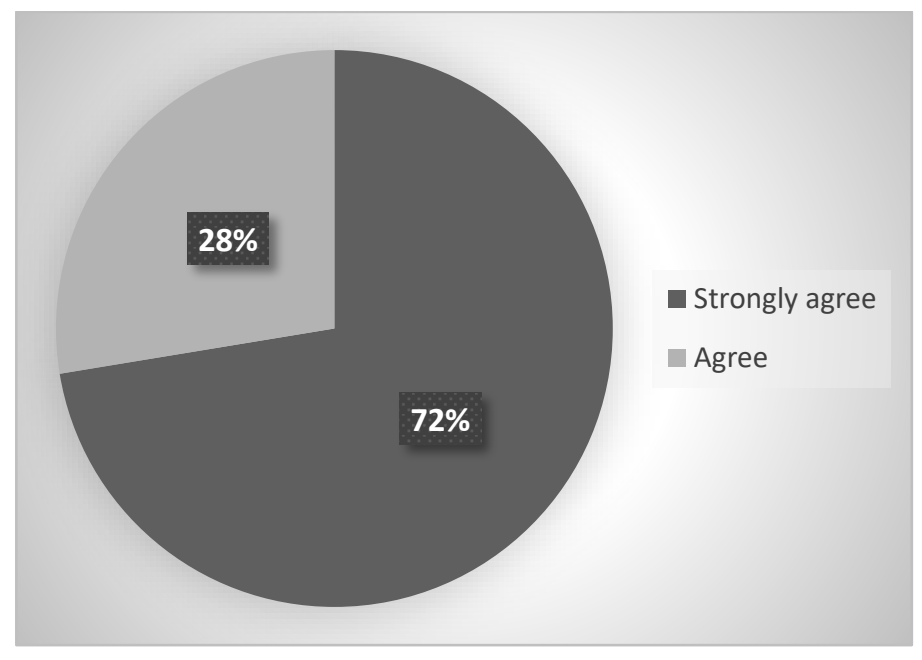

Figure 5: Enhanced interest and motivation towards Biochemistry subject

Some of the feedbacks regarding the impacts of using metabolic town illustration in the three glucose metabolism topics are recorded below:

"Look at the colors, storyline, it only includes the important ones, not too much information and it has helped me. Thank you so much!”- Learner 1

"All the topics/subtopics are simplified in a paper and it was easy to understand"- Learner 2

"The most favorite part is the color and the storyline. Not using long sentences to describe; easy to understand" - Learner 3

"The drawing makes it easier for me to understand"- Learner 4

According to Figure 6, 90\% of the learners strongly agree that the visual illustration aided them 
during the revision process. According to Mohanty (2001), the use of illustration is favorable in teaching-learning process. Hence, this finding is in line with this theory. Also, as reported by (Shabiyalrani et al., 2015), the illustration must be adequate to be seen easily by the learners farthest from the aids. Colors should provide a clear contrast and easily be visible. Lastly, nearly $90 \%$ of the learners agreed that the use of illustration improved their understanding of the particular topics (Figure 7). Hence, the use of illustration is good to help revive the learners or keep them active in the teaching and learning process.

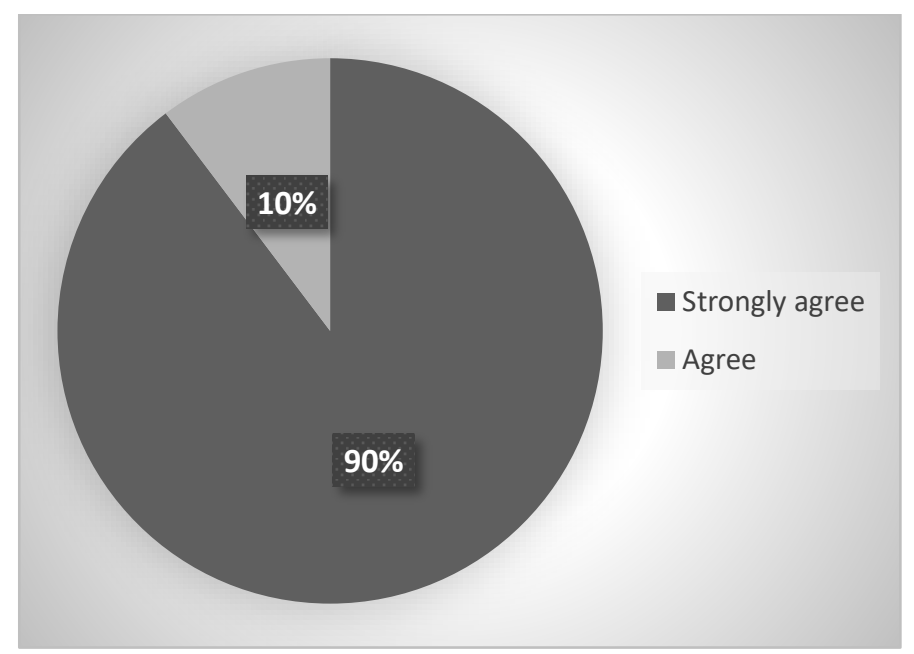

Figure 6: The illustration aids revision process

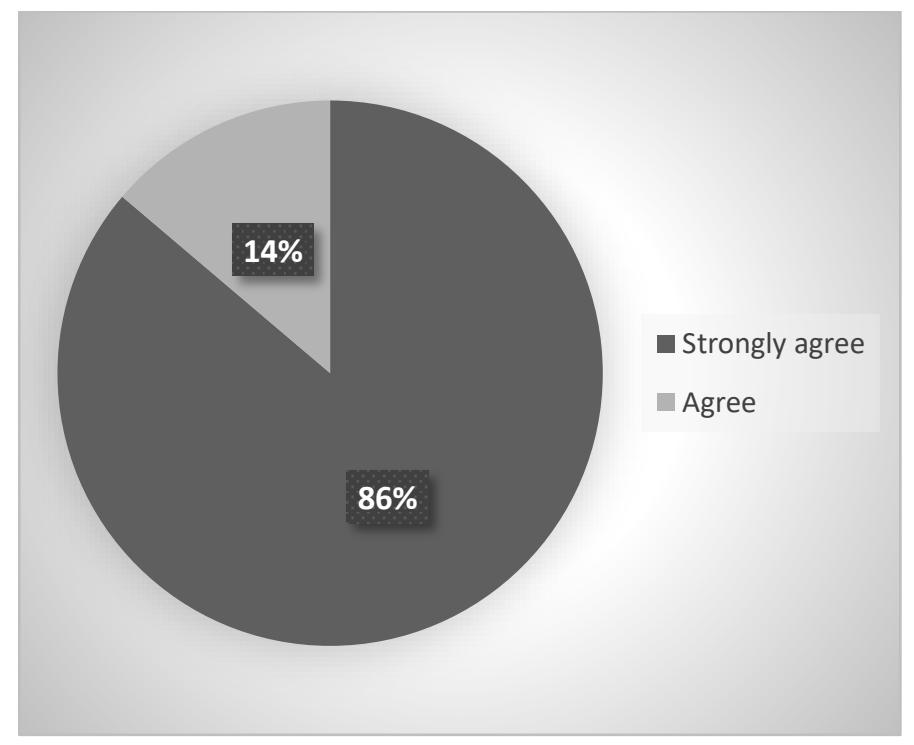

Figure 7: Improved understanding of the particular topic

\section{CONCLUSION}

Based on the research, it is clearly shown that one of the main goals of teaching is for the learners to be able to retain as much knowledge of the topic as possible, particularly the crucial points. Additionally, from this study, several conclusions have been deduced; 
- The study concluded that using illustration as a supplementary teaching tool stimulates interest and improves learning experience in a classroom.

- Illustration substitutes dull learning ambiances.

- Learners develop better and increased understanding of a lesson when they have pleasant learning experience in the classroom.

- Learners find illustration useful when it has some direct relation and use ideal analogy relevant to the course content. The present research gave insights on learners' perceptions and opinions on the use of illustration resources.

Illustrations have enormous potential as tools for teaching and learning. They must however be selected carefully and used properly. Learners can learn to see and think when illustration is used and the impacts can be magical too. Isn't that what education is about?

\section{ACKNOWLEDGEMENT}

The author wishes to express her gratitude to the Talent Development and Innovation Center, the e-Learning Unit, Data and Digital Development Center, and the Faculty of Science and Marine Environment, Universiti Malaysia Terengganu (UMT) for the unconditional support. Special appreciation to Semester II 2019/2020 Biochemistry teaching team and students for the endless encouragement.

\section{REFERENCES}

Arts Council Englandhttps://clpe.org.uk/powerofpictures/creative-approaches/1 (accessed July, 5 2020)

Carney, R.N and Joel R. Levin, J.R. 2002. Pictorial Illustrations Still Improve Students' Learning from Text. Educational Psychology Review 14(1): 5-26.

Dretzke, B.J. 1993. Effects of pictorial mnemonic strategy usage on prose recall of young, middle-aged, and older adults. Educational Gerontology 19: 489-502.

McCormick, C. B. and Levin, J. R. 1987. Mnemonic prose-learning strategies. In Imagery and Related Mnemonic Processes Theories, eds. McDaniel, M. A., and Pressley, 392-406. New York: Springer.

Mohanty, J. 2001. Educational Technology. Publish by Rajouri garden New Delhi.

Peeck, J. 1993. Increasing picture effects in learning from illustrated text. Learning Instruction 3(3): 227-238.

Quillin, K and Thomas, S. 2015. Drawing-to-Learn: A Framework for Using Drawings to Promote Model-Based Reasoning in Biology. Life Sciences Education, 14, 1-16.

Rubman, C. N.and Waters, H. S. 2000. A, B seeing: The role of reconstructive processes in children's comprehension monitoring. Journal of Educational Psychology 92(3): 503514.

Sevarkadiyon, A. and Parimafathima, M .2019. Assessing the Effectiveness of Scientific Illustration as a Learning Tool in the Classroom through Self-Regulated Learning (Srl). IOSR Journal of Research \& Method in Education 4(5): 1-3.

Shabiralyani, G., Hasan, K.S., Hamad, N. Iqbal, N. 2015. Impact of Visual Aids in Enhancing the Learning Process Case Research: District Dera Ghazi Khan. Journal of Education and Practice 6(19): 226-233. 
AZILA ADNAN

Universiti Malaysia Terengganu,

Faculty of Science and Marine Environment,

21030, Kuala Nerus, Terengganu

*Corresponding author: azila.adnan@umt.edu.my 